\title{
High antibacterial properties of green synthesized gold nanoparticles using Uncaria gambir Roxb. leaf extract and triethanolamine
}

\author{
Syukri Arief*, Fri Wardana Nasution, Zulhadjri, Arniati Labanni \\ Department of Chemistry, Faculty of Mathematics and Sciences, Andalas University, Padang 25163, Indonesia.
}

\section{ARTICLE INFO \\ Received on: 25/06/2019 \\ Accepted on: 24/01/2020 \\ Available online: 05/08/2020}

\section{Key words:}

Green synthesis, gold nanoparticles, Uncaria gambir Roxb., triethanolamine, biomedical applications, bioreducing agent.

\begin{abstract}
The development of antibacterial agents is increasingly gaining much attention due to the expansion activity of multi-drug resistant bacteria in causing many diseases. Metallic nanoparticles especially gold nanoparticles in the field of nanotechnology is one of the new and significant materials to be developed as antibacterial agents. Gold nanoparticles have been successfully synthesized using Uncaria gambir Roxb. leaf extract as a bioreducing agent and triethanolamine as a capping agent, through reduction of $\mathrm{Au}^{+3}$ by flavonoid compound in the leaf extract. The effect of triethanolamine and hydrogen tetrachloroaurate (III) acid concentration on the stability and size of nanoparticles was studied. The presence of triethanolamine $1 \%$ as a capping agent successfully maintained the stability of colloidal gold nanoparticles with a concentration of hydrogen tetrachloroaurate (III) acid at $100 \mathrm{ppm}$. X-Ray Diffraction analysis showed peak patterns corresponding to the metallic gold standard with a crystallite size of $32.52 \mathrm{~nm}$. Transmission Electron Microscope analysis showed that particles were spherical, hexagonal, and triangular, where the smallest particle size was $7 \mathrm{~nm}$. Synthesized gold nanoparticles showed great antibacterial activity against E. coli and S. aureus. The stability and antibacterial activity of synthesized gold nanoparticles showed good potential to be developed in biomedical applications.
\end{abstract}

\section{INTRODUCTION}

Pathogenic bacteria are bacteria that cause diseases in humans through water, food, and clothes. Some medical treatments, predominantly drugs, are used and developed to cure some bacteriacaused diseases. However, instead of curing the diseases, nowadays, people prefer to prevent the bacteria infection by combining certain antibacterial agents into things such as food containers, cosmetics, clothes, and surgery kits (Abbasi et al., 2016). For this purpose, antibacterial agent development is currently gaining some attention. In this point, nanotechnology offers a promising approach to develop and modify the excellent properties of metal nanoparticles for biomedical application goals (Franci et al., 2015).

Nanotechnology is the study of the synthesis, strategy, and structure manipulation of materials in the size of $1-100 \mathrm{~nm}$

"Corresponding Author

Syukri Arief, Department of Chemistry, Faculty of Mathematics and Sciences, Andalas University, Padang 25163, Indonesia.

E-mail:syukriarief@sci.unand.ac.id
(Iravani, 2011; Moodley et al., 2018). Recently, the study of nanotechnology has drawn a lot of attention due to the excellent properties which are fundamentally different in chemical, physical, and biological aspects in the bulk materials (Heiligtag and Niederberger, 2013). One of the most developed fields is metallic nanoparticles which have been widely applied in medical application, such as in body tissue repair, gene delivery, drug delivery, immunodiagnostic, optic, food industry, environment, and imaging (Ahmed and Ikram, 2015; He et al., 2019; Kim et al., 2012; Marza et al., 2019). The application is based on the potential of the metallic nanoparticles to act as antibacterial agents due to the nanometer size and high surface to volume ratio (Khalil et al., 2013). Among all the metals, silver and gold are the most developed because of their high potential as antibacterial agents (Dykman and Khlebtsov, 2012). Besides, it is due to the high ability to functionalization, nontoxicity, ease of detection, and photothermal activity (Dizaj et al., 2014). Some studies proposed that the antibacterial activity mechanism of metal nanoparticles relates to toxic-free metal ion which arises from the surface of nanoparticles and infiltrated into bacteria cell. These toxic metal ions were then accumulated in the cell membrane and disturb 
the metabolism of the cell, leading to cell death. In addition, this is might be due to the nano size of the metal particles for easy entrance into the cell (Dizaj et al., 2014; Labanni et al., 2019; Parham et al., 2016).

Various methods can be used to fabricate gold nanoparticles, such as reduction method (Heidari et al., 2014), hydrothermal (Tippayawat et al., 2016), microwave (Ngo et al., 2016), and laser irradiation (Gonzalez-Rubio et al., 2016), and many other. Among the methods, chemical reduction is the most favorable because of its simplicity and low-energy requirements (Elia et al., 2014). However, the utilization of hazardous chemical reagents can be toxic and threaten the environment and living organisms. Hence, an environmental green synthesis method is currently developed by the researchers to reduce the dangerous impacts. In this method, some types of living organisms are used as bioreducing agents, such as plants, algae, and fungi, whose active compounds were used (Shah et al., 2015).

Uncaria gambir (U. gambir) Roxb. is a species of flowering plant found in West Sumatera. For a long time, it has been used in materials such as tanner base material for dyeing, pesticide, glue plywood, and especially as medicine to heal illnesses due to the content of catechin, which are classified as flavonoid compounds, up to $33 \%$ (Fauza, 2014). In this study, U. gambir Roxb. leaf extract was used as a bioreducing agent to synthesize gold nanoparticles. In our previous studies, we have successfully synthesized silver nanoparticles by employing $U$. gambir Robx. as a bioreducing agent by the hydrothermal method in water solvent (Arief et al., 2015), in isopropanol solvent (Arief et al., 2017), and also by reduction method in the presence of diethanolamine (Labanni et al., 2018). To the best of our knowledge, this is the first report of the study on the synthesis of gold nanoparticles using $U$. gambir Roxb. as a bioreducing agent.

In addition, a stabilizer agent is necessary to be added to the reaction to control the growth and the size of the particles to form stable colloidal nanoparticles (Patel et al., 2017). This control is substantial for the medical application since the antibacterial activity is strongly affected by size, shape, and concentration of the nanoparticles (Franci et al., 2015). Hence, in this study, we use triethanolamine as a capping agent. The concentration of $\mathrm{HAuCl}_{4}$ as a precursor was also varied to investigate the effect of concentration on the properties of gold nanoparticles.

\section{MATERIALS AND METHODS}

\section{Materials}

$\mathrm{HAuCl}_{4}$ as the precursor and triethanolamine (TEA) as the capping agent in the synthesis were purchased from Merck. Fresh U. gambir Roxb. leaves were taken from Payakumbuh, West Sumatera, Indonesia. Uncaria gambir Roxb. was identified and deposited at Herbarium Universitas Andalas (ANDA) Padang, Indonesia with specimen number of 01AL-Arniati Labanni.

\section{Preparation of Uncaria gambir Roxb. leaf extract}

First, U. gambir Roxb. leaves were washed with tap water to remove dirt, and then were shade-dried for a week at room temperature. Furthermore, gambir leaves were mashed using a grinder to obtain a powder. The powder was then stored in a dark sealed container and protected to prevent damage and deterioration.
Plant extracts were obtained by weighing $10 \mathrm{~g}$ of plant powder, which were then added with $100 \mathrm{ml}$ of distilled water and heated at $60^{\circ} \mathrm{C}$ for 2 hours. The mixture was then filtered to obtain the extract. The extract was stored in the refrigerator for future use.

\section{Synthesis of gold nanoparticles}

Every $25 \mathrm{ml}$ of $\mathrm{HAuCl} 4$ solution with concentrations 20 and $100 \mathrm{ppm}$ was mixed with $10 \mathrm{ml}$ of $1 \%$ TEA and $15 \mathrm{ml}$ of $6 \%$ U. gambir Roxb. extract to a total volume of $50 \mathrm{ml}$. These mixtures were then stirred for 6 hours at room temperature. The formation and growth of colloidal gold nanoparticles were monitored periodically using ultra violet - visible (UV-Vis) spectrophotometer (510000 SECOMAM). The colloidal gold nanoparticles without TEA as a capping agent were also prepared with the same precursor concentration. The TEA stabilized gold nanoparticles were then coded as AuNps-1 and AuNps-2 for using 20 and $100 \mathrm{ppm} \mathrm{HAuCl}_{4}$, respectively. The unstabilized gold nanoparticles were coded as AuNps-3 and AuNps-4 for the

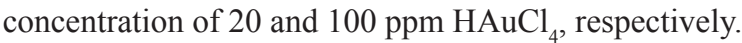

\section{Characterization}

The crystallinity of AuNps was studied using X-ray diffraction (XRD) Phillips X'pert Powder PAN analytical with radiation of $\mathrm{CuK}(\lambda=1,5406 \AA)$ operated at $30 \mathrm{kV}$ and $30 \mathrm{~A}$. The powder sample of AuNps was prepared by precipitating the colloidal AuNps. The obtained solid was separated from the filtrate, then washed with distilled water, and dried in a hot air oven to obtain the powder AuNps. The size distribution and image of colloidal AuNps shape were studied using transmission electron microscope (TEM) JEOL JEM 1400.

\section{Antibacterial activity test}

The as-synthesized U. gambir Roxb. mediated AuNps were tested against Escherichia coli and Staphylococcus aureus bacteria using the disc diffusion or Kirby Bauer method. Nutrient agar medium was used to cultivate bacteria. Fresh overnight bacteria culture was taken and $100 \mu$ l of inoculum was spread on nutrient agar (NA) agar plates. Sterile paper discs of $5 \mathrm{~mm}$ diameter (containing $50 \mu \mathrm{g} / \mathrm{ml}$ AuNps) were placed in each plate, along with positive and negative control. Positive and negative control used in the test were water and amoxicillin, respectively. After incubating for 24 hours at $37^{\circ} \mathrm{C}$, the inhibition zone of the samples was measured. The test was conducted in duplicate, and all data reported are average values.

\section{RESULTS AND DISCUSSION}

\section{UV-Vis spectrophotometer study}

The formation of gold nanoparticles were then confirmed using the UV-Vis spectrophotometer at a wavelength of 515-570 $\mathrm{nm}$ based on surface plasmon resonance (SPR) phenomenon. The result of the UV-Vis spectrophotometer (Fig. 1) provides a spectrum of the U. gambir Roxb. extract, which shows a peak at $279 \mathrm{~nm}$, referred to catechin. When reacted with $\mathrm{HAuCl} 4$, the absorption peak shifted to a wavelength of $534 \mathrm{~nm}$, which confirmed the formation of gold nanoparticles, indicating that $\mathrm{Au}^{3+}$ ions have been successfully reduced to $\mathrm{Au}^{0}$ by the content of catechin in U. gambir Roxb. leaf extract. This is in accordance with the previous synthesis by Yu et al. (2016) using Citrus maxima aqueous extract and Paul 
et al. (2015) using Pogestemon benghalensis which showed the local surface plasmon resonance (LSPR) band of gold nanoparticles at 535-538 $\mathrm{nm}$ and $510-560 \mathrm{~nm}$, respectively.

In spectrophotometry analysis, it was observed that the concentration and the utilization of capping agents strongly affect the optical properties of the gold nanoparticles. TEA capped AuNps both at $\mathrm{HAuCl}_{4}$ concentration of $20 \mathrm{ppm}$ (AuNps-1) and at a concentration of $100 \mathrm{ppm}$ (AuNps-2), showing better stability than non-stabilized AuNps both at a concentration of $20 \mathrm{ppm}$ (AuNps-3) and at a concentration of 100 ppm (AuNps-4). AuNps-1 and AuNps-2 did not show precipitation until the reaction time of 168 hours, while in AuNps-3 and AuNps-4, the precipitation was observed after 24-hour reaction time. The precipitation of the nanoparticles occurs due to the agglomeration. It is caused by the growth and the van der walls interaction among the nanoparticles (Sinha and Mukherjee, 2014). The use of a capping agent or stabilizer can minimize the interaction between nanoparticles, thus preventing the excess growth of nanoparticles which causes agglomeration (Chu et al., 2018). In this study, results have shown that the use of TEA as a capping agent successfully prevented or delayed the occurrence of agglomeration and deposition of nanoparticles up to seven times.
In addition, the results exhibited that the concentration of the $\mathrm{HAuCl}_{4}$ precursor can affect the speed of agglomeration and precipitation of nanoparticles. It was observed in the TEA-unstabilized gold nanoparticles where the AuNps-3 was precipitated before 24 hours and AuNps- 4 was precipitated after 24 hours. In contrast, the TEA-stabilized AuNps-1 and AuNps-2 showed good stability and did not show precipitation until 168 hours. These results showed that TEA can maintain the stability of the gold nanoparticles even with $5 \times$ precursor concentration.

The formation of nanoparticles was also investigated using laser beam radiation based on the Tyndall effect. The inset picture in Figure 1 showed the laser beam radiation on AuNps-1 in the time reaction of 0,2 , and 24 hours. It was observed that light was dispersed in the colloid, which confirmed the scattering of the light by the particles. The color of the colloidal nanoparticles turned dense after some time, which confirmed that the number of colloidal nanoparticles increased continuously during the reaction.

The wavelength and absorbance values of $U$. gambir Roxb. mediated gold nanoparticles characterized by the UV-Vis spectrophotometer are presented in Table 1. It shows that the absorbance of the nanoparticles was increased with the increase of concentration from 20 to $100 \mathrm{ppm}$ of the precursor, both in

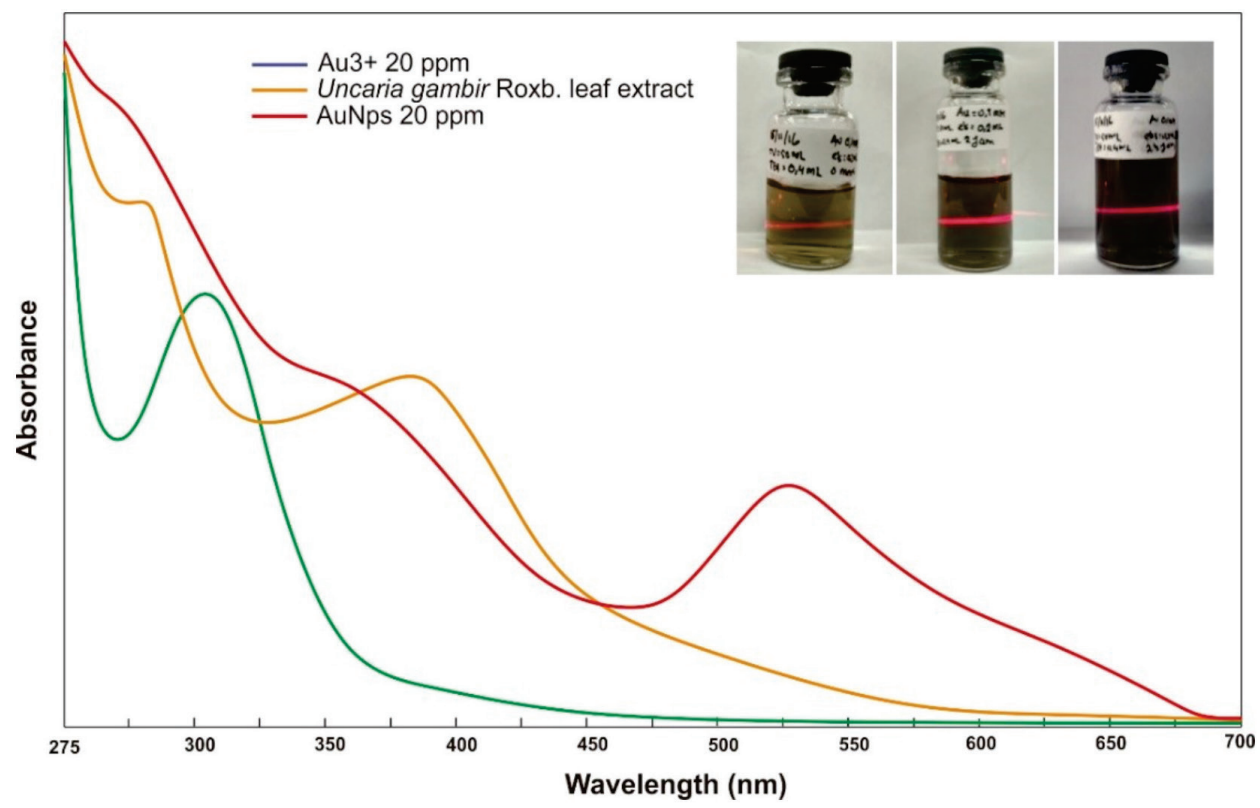

Figure 1. UV-Vis spectra before and after reaction. Inset shows the laser beam radiation after a. 0 hour, b. 2 hours, and c. 24 hours.

Table 1. Absorbance and wavelength value of $U$. gambir Roxb. mediated colloidal gold nanoparticles.

\begin{tabular}{ccccccccc}
\hline \multirow{2}{*}{ Reaction Time (h) Wavelength (nm) } & \multicolumn{5}{c}{ Absorbance } \\
\cline { 2 - 10 } & AuNps-1 & AuNps-2 & AuNps-3 & AuNps-4 & AuNps-1 & AuNps-2 & AuNps-3 & AuNps-4 \\
\hline 0.5 & - & - & - & 545 & - & - & - & 1.688 \\
1 & - & - & 515 & 543 & - & - & 0.338 & 1.939 \\
2 & 541 & 555 & 515 & 538 & 0.271 & 1.158 & 0.339 & 2.055 \\
4 & 541 & 560 & 515 & 538 & 0.318 & 1.241 & 0.346 & 2.258 \\
6 & 544 & 565 & 515 & 538 & 0.331 & 1.447 & 0.352 & 2.295 \\
24 & 534 & 570 & 520 & 535 & 0.426 & 0.577 & 0.376 & 2.355 \\
168 & 534 & - & 522 & 534 & 0.407 & - & 0.402 & 2.313 \\
\hline
\end{tabular}


TEA stabilized and unstabilized gold nanoparticles. This result suggested that the higher concentration of the precursor leads to the increase of nanoparticles formed in the reaction. In addition, the wavelength values showed similar results, where a higher concentration provides a higher wavelength value.

\section{Crystallinity study}

The crystalline nature of synthesized Au nanoparticles was further studied by XRD analysis. Figure 2 shows the XRD pattern of powdered $\mathrm{Au}$ nanoparticles. Five distinct peaks were observed at $38.22^{\circ}(111), 44.41^{\circ}(200), 64.62^{\circ}(220), 77.73^{\circ}(311)$, and $81.77^{\circ}(222)$ which referred to a well crystalline face-centered cubic (FCC) gold nanoparticles, based on the International center for diffraction data (ICDD) standard 039065-2870. This result was in agreement with previous studies which used Citrus maxima (Yu et al., 2016), Pogestemon benghalensis leaf extract (Paul et al., 2015), Stevia rebaudiana leaf extract (Sadeghi et al., 2015), and Lantana camara leaf extract (Dash et al., 2015). Based on the Debye-Scherrer formula, Au crystallite size was estimated to be $32.5 \mathrm{~nm}$ which is slightly smaller than the crystallite size $(36.28$ $\mathrm{nm}$ ) reported by Li et al. (2016) by studying the gold nanoparticles synthesized using extreme bacterium Deinococcus radiodurans.

\section{Morphology study}

The results of TEM analysis AuNPs-1, AuNps-2, AuNps-3, and AuNps-4, which have been synthesized, can be seen in Figure 3. It was observed that the synthesized gold nanoparticles have a variety of shapes such as hexagonal, triangular, and, predominately, round shapes. This TEM result showed that the use of TEA as a capping agent in various concentrations affected the particle size. The particle size distribution of AuNps-1, AuNps-2, AuNps-3, and AuNps-4 was obtained as seen in Figure $4 a-4 d$, respectively.

The particle size ranges of AuNps-1, AuNps-2, AuNps-3, AuNps-4 were 13-82 nm, 4-16 nm, 10-56 nm, and 11-62 nm, respectively, with an average size of $29,11,23$, and $31 \mathrm{~nm}$, respectively. The TEA unstabilized gold nanoparticles showed that the increase of precursor concentration leads to an increase

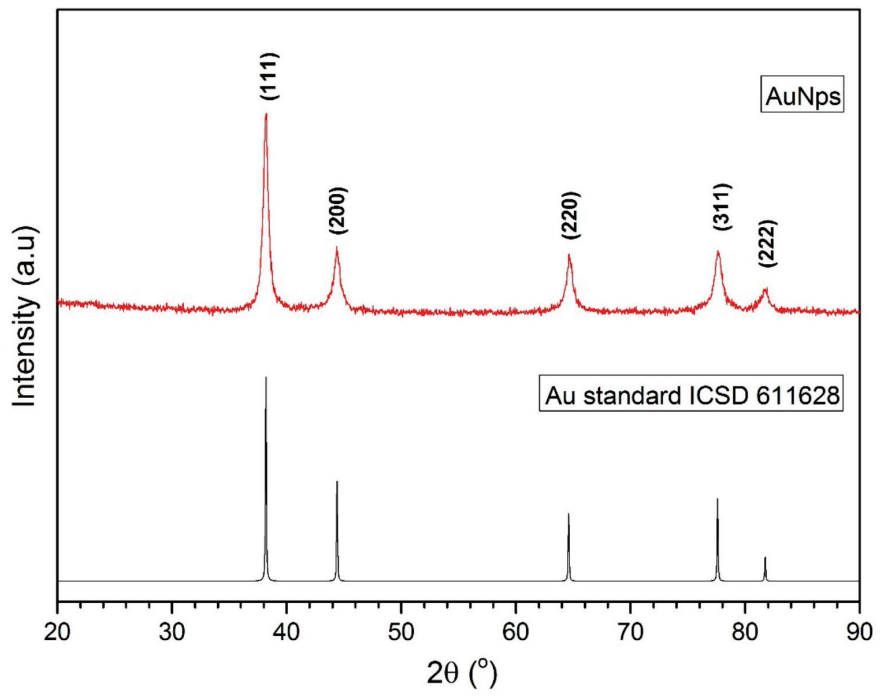

Figure 2. XRD pattern of AuNps powder. in size. Different from the TEA stabilized gold nanoparticles, the increase in concentration did not exhibit any effect on the particle size. These results suggested that TEA successfully maintained the particle size of gold nanoparticles even in larger concentration synthesis. The nitrogen element in TEA is expected to play a crucial role in the capping mechanism of gold nanoparticles. The interaction between positively surface charged gold nanoparticles and positively charged nitrogen forms a protective monolayer on the surface of gold nanoparticles. This protective monolayer prevents excessive interaction among the gold nanoparticles, hence preventing aggregation and controlling the growth of gold nanoparticles (Yamamoto et al., 2006).

\section{Antibacterial activity study of Uncaria gambir Roxb. mediated gold nanoparticles}

Figure 5 shows well-defined zones of inhibition of gold nanoparticles against $S$. aureus (a) and $E$. coli (b), as a representative of gram-positive and gram-negative bacteria. The inhibition zone of the sample was shown in Table 2. The test was conducted in duplicate, and all the data reported are average values.

The inhibition zone of AuNps-1, AuNps-2, AuNps-3, and AuNps-4 were 6, 7, 6, and $6 \mathrm{~mm}$ against $S$. aureus and 8, 9, 7, 6, mm against E. coli, respectively. Whereas amoxicillin as a positive control was measured to be $4 \mathrm{~mm}$ against $S$. aureus and $5 \mathrm{~nm}$ against $E$. coli.

A slightly higher inhibition zone of AuNps was observed in the test against $E$. coli than the test against $S$. aureus. This is due to the difference in cell wall composition between positive strain and negative strain bacteria. The peptidoglycan layer in negative strain bacteria is thinner than that in positive strain bacteria, making AuNps to easily enter the cytoplasm. The detailed mechanism of the antibacterial activity of AuNps is currently studied and will be reported in the next paper.

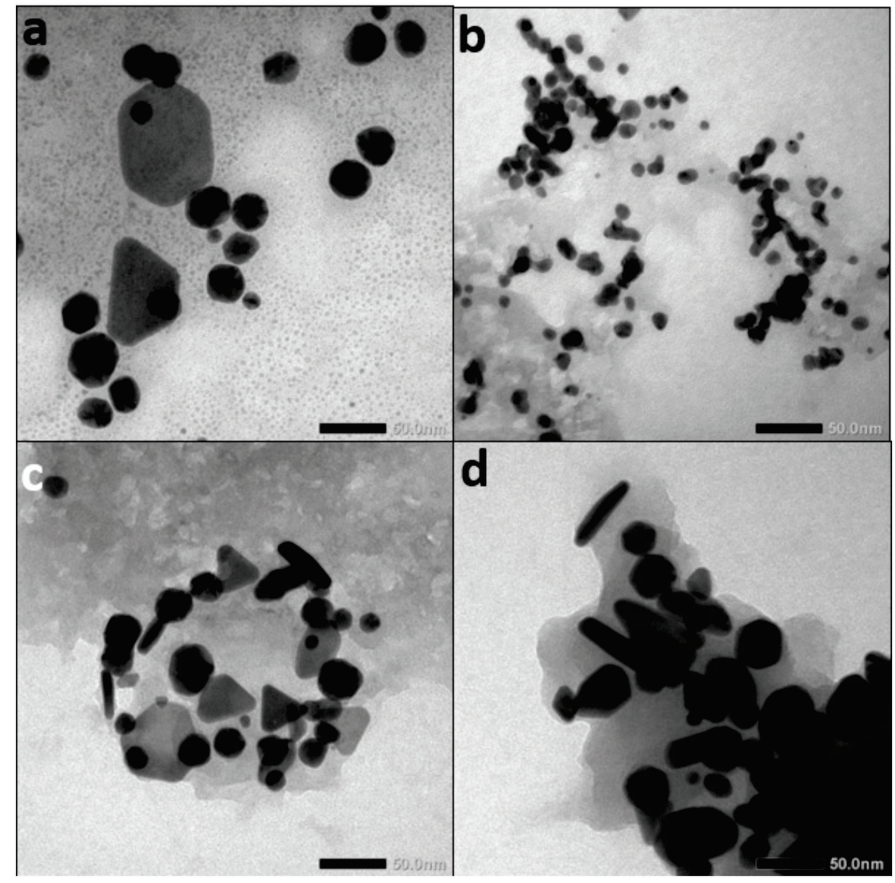

Figure 3. TEM images of a) AuNps-1, b) AuNps-2, c) AuNps-3, and d) AuNps-4 


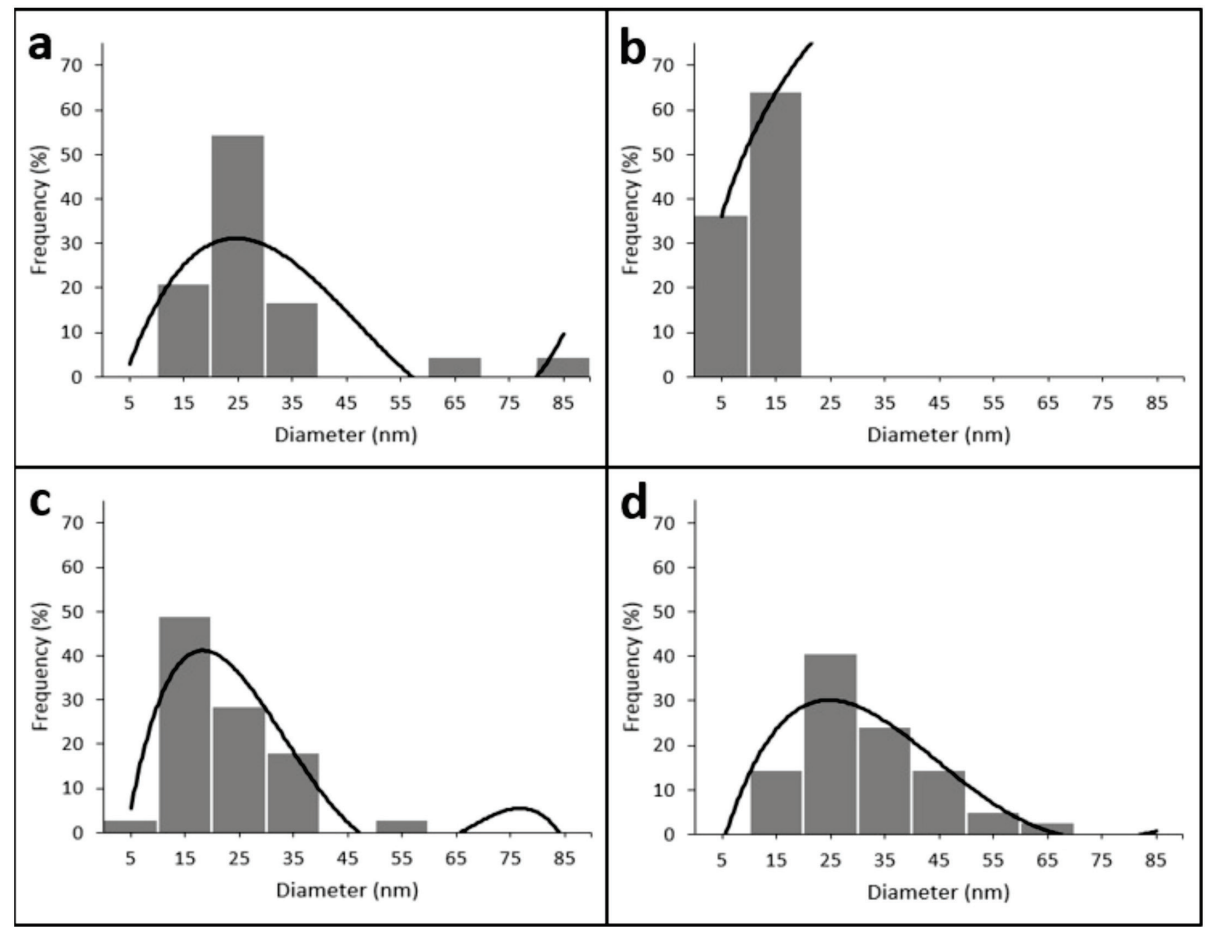

Figure 4. Particles size distribution of a) AuNps-1, b) AuNps-2, c) AuNps-3, and d) AuNps-4.
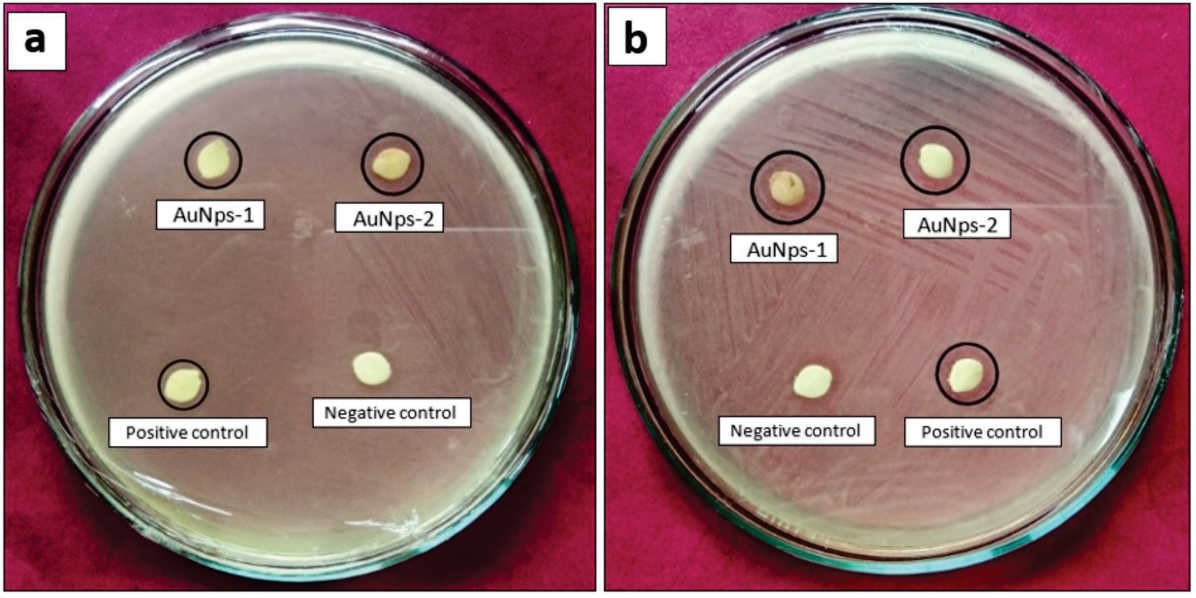

Figure 5. Antibacterial activity of gold nanoparticles against a) S. aureus and b) E. Coli.

Table 2. Inhibition zone of gold nanoparticles.

\begin{tabular}{lcccccc}
\hline \multirow{2}{*}{ Bacteria } & \multicolumn{5}{c}{ Inhibition zone (mm) } \\
\cline { 2 - 8 } & $(-)$ controll & $(+)$ controll & AuNPs-1 & AuNPs-2 & AuNPs-3 & AuNPs-4 \\
\hline S. aureus & - & 4 & 6 & 7 & 6 & 6 \\
E. coli & - & 5 & 8 & 9 & 7 & 6 \\
\hline
\end{tabular}

The results showed that different $\mathrm{HAuCl}_{4}$ concentrations in synthesizing gold nanoparticles did not show any significant effect on the inhibition zone. In addition, a higher inhibition zone was performed by AuNps-2 both against $S$. aureus and E. coli. This might be due to the size of AuNps which allowed it to easily enter into the cytoplasm of the cell. AuNps stimulated the formation of biofilm and interacted with the element of the cell wall, leading to the change of the structure, degradation, and hence the death of the cell. While interacting, AuNps was trapped in the biofilm and released some compounds, which caused a distortion in the cell wall. Some previous studies on green synthesized gold nanoparticles and their antibacterial activity with the comparison to our samples are shown in Table 3. These results showed that $U$. gambir Roxb. mediated gold nanoparticles with TEA since capping agents have the potential to be developed as antibacterial agents in biomedical applications. 
Table 3. Comparison of particle size and inhibition zone of green synthesized gold nanoparticles.

\begin{tabular}{|c|c|c|c|c|}
\hline Extract & Average particles size (nm) & Bacteria strains & Inhibition zone (mm) & References \\
\hline \multirow{2}{*}{ Gloriosa superb leaf extract } & \multirow{2}{*}{20} & B. subtilis & - & \multirow{2}{*}{ (Gopinath et al., 2016) } \\
\hline & & E. coli & - & \\
\hline \multirow{2}{*}{ Deinococcus radiodurans bacteria } & \multirow{2}{*}{43.75} & S. aureus & $8.95 \pm 0.17$ & \multirow{2}{*}{ (Li et al., 2016) } \\
\hline & & E. coli & $9.21 \pm 0.20$ & \\
\hline \multirow{2}{*}{ Nephentes khasiana leaf extract } & \multirow{2}{*}{50} & Bacillus sp. & 10.0 & \multirow{2}{*}{ (Bhau et al., 2015) } \\
\hline & & E. coli & 8.0 & \\
\hline \multirow{2}{*}{ U. gambir Roxb leaf extract } & \multirow{2}{*}{11} & S. aureus & 7 & \multirow{2}{*}{ this work } \\
\hline & & E. coli & 9 & \\
\hline
\end{tabular}

\section{CONCLUSION}

Gold nanoparticles of different shapes and sizes were successfully synthesized using $U$. gambir leaf extract by the addition of TEA and varying the concentration. The UV-Vis spectrophotometry analysis confirmed the formation of AuNps by SPR absorption at a wavelength of 515-570 $\mathrm{nm}$. The XRD analysis results showed the formation of high-crystalline FCC-structured AuNps. The TEM analysis result showed that the formed AuNps were spherical, hexagonal, and triangular with $4-82 \mathrm{~nm}$ in size. The utilization of TEA as a capping agent can maintain the particle size, even in $5 \times$ precursor concentration. The prepared AuNps showed excellent antibacterial activity against $E$. coli and $S$. aureus.

\section{ACKNOWLEDGEMENT}

The authors would like to thank Ministry of Research, Technology and Higher Education of the Republic of Indonesia via LPPM of Andalas University for funding this research.

\section{CONFLICT ON INTEREST}

Authors declared that they do not have any conflicts of interest.

\section{REFFERENCES}

Abbasi E, Milani M, Aval SF, Kouhi M, Akbarzadeh A, Nasrabadi HT, Nikasa P, Joo SW, Hanifehpour Y, Nejati-Koshki K, Samiei M. Silver nanoparticles: synthesis methods, bio-applications and properties. Crit Rev Microbiol, 2016; 42:173-80.

Ahmed S, Ikram S. Synthesis of gold nanoparticles using plant extract: an overview. Nano Res Appl, 2015; 1:1-6.

Arief S, Gustia V, Wellia DV, Zulhadjri BT, Ohya Y. Hydrothermal synthesized $\mathrm{Ag}$ nanoparticles using bioreductor of gambier leaf extract (Uncaria gambier Roxb). J Chem Pharm Res, 2015; 7:189-92.

Arief S, Hidayani P, Aferta L, Zulhadjri, Ban T, Ohya Y. Green chemistry formation of stable Ag nanoparticles (AgNPs) in isopropanol solvent. Orient J Chem, 2017; 33:87-91.

Bhau BS, Ghosh S, Puri S, Borah B, Sarmah DK, Khan R. Green synthesis of gold nanoparticles from the leaf extract of Nepenthes khasiana and antimicrobial assay. Adv Mater Lett, 2015; 6:55-8.

Chu Z, Han Y, Kral P, Klajn R. Precipitation on nanoparticles: attractive intermolecular interactions stabilize specific ligand ratios on the surfaces of nanoparticles. Angew Chemie Int Ed, 2018; 57.

Dash SS, Bag BG, Hota P. Lantana camara Linn leaf extract mediated green synthesis of gold nanoparticles and study of its catalytic activity. Appl Nanosci, 2015; 5:343-50.

Dizaj SM, Lotfipour F, Barzegar-Jalali M, Zarrintan MH, Adibkia $\mathrm{K}$. Antimicrobial activity of the metals and metal oxide nanoparticles. Mater Sci Eng C, 2014; 44:278-84.

Dykman L, Khlebtsov N. Gold nanoparticles in biomedical applications: recent advances and perspectives. Chem Soc Rev, 2012; 41:2256-82.

Elia P, Zach R, Hazan S, Kolusheva S, Porat Z, Zeiri Y. Green synthesis of gold nanoparticles using plant extracts as reducing agents. Int J Nanomedicine, 2014; 9:4007-21.

Fauza H. Gambier : Indonesia leading commodities in the past Int J Adv Sci Eng Inf Technol, 2014; 4:67-72.

Franci G, Falanga A, Galdiero S, Palomba L, Rai M, Morelli G, Galdiero M. Silver nanoparticles as potential antibacterial agents. Molecules, 2015; 20:8856-74.

Gopinath K, Kumaraguru S, Bhakyaraj K, Mohan S, Venkatesh KS, Esakkirajan M, Kaleeswarran P, Alharbi NS, Kadaikunnan S, Govindarajan M, Benelli G, Arumugam A. Green synthesis of silver, gold and silver/gold bimetallic nanoparticles using the Gloriosa superba leaf extract and their antibacterial and antibiofilm activities. Microb Pathog, 2016; 101:1-11.

He X, Deng H, Hwang HM. The current application of nanotechnology in food and agriculture. J Food Drug Anal, 2019; 27:1-21.

Heidari Z, Sariri R, Salouti M. Journal of Photochemistry and photobiology $\mathrm{B}$ : biology gold nanorods-bombesin conjugate as a potential targeted imaging agent for detection of breast cancer. J Photochem Photobiol B Biol, 2014; 130:40-6.

Heiligtag FJ, Niederberger $M$. The fascinating world of nanoparticle research. Biochem Pharmacol, 2013; 16:262-71.

Iravani S. Green synthesis of metal nanoparticles using plants. Green Chem, 2011; 13:2638-50.

Khalil KA, Fouad H, Elsarnagawy T, Almajhdi FN. Preparation and characterization of electrospun PLGA/silver composite nanofibers for biomedical applications. Int J Elctrochemical Sci, 2013; 8:3483-93.

Kim EY, Schulz R, Swantek P, Kunstman K, Malim MH, Wolinsky SM. Gold nanoparticle-mediated gene delivery induces widespread changes in the expression of innate immunity genes. Gene Ther 2012; 19:347-53.

Labanni A, Zulhadjri Z, Handayani D, Ohya Y. The effect of monoethanolamine as stabilizing agent in Uncaria gambir Roxb. mediated synthesis of silver nanoparticles and its antibacterial activity. J Dispers Sci Technol, Taylor \& Francis; 2019:1-8.

Labanni A, Zulhadjri, Handayani D, Arief S. Uncaria gambir Roxb. mediated green synthesis of silver nanoparticles using diethanolamine as capping agent. IOP Conf Ser Mater Sci Eng, 2018; 299:1-6.

Li J, Li Q, Ma X, Tian B, Li T, Yu J, Dai S, Weng Y, Hua Y. Biosynthesis of gold nanoparticles by the extreme bacterium Deinococcus radiodurans and an evaluation of their antibacterial properties. Int $\mathrm{J}$ Nanomedicine, 2016; 11:5931-44.

Marza SM, Magyari K, Bogdan S, Moldovan M, Pestean C, Nagy A, Tabaran F, Licarete E, Suarasan S, Dreanca A, Baia L, Papuc I. Skin wound regeneration with bioactive glass-gold nanoparticles ointment. Biomed Mater, 2019; 14.

Moodley JS, Krishna SBN, Pillay K, Govender P. Green synthesis of silver nanoparticles from Moringa oleifera leaf extracts and its antimicrobial potential. Adv Nat Sci Nanosci Nanotechnol, 2018; 9:1-9.

Ngo VKT, Nguyen DG, Huynh TP, Lam QV. A low cost technique for synthesis of gold nanoparticles using microwave heating and its application in signal ampli fi cation for detecting Escherichia Coli O157 : H7 bacteria. Adv Nat Sci Nanosci Nanotechnol, 2016; 7:1-9.

Parham S, Wicaksono DHB, Bagherbaigi S, Lee L, Nur H. Antimicrobial treatment of different metal oxide nanoparticles : a critical review. J Chinese Chem Soc, 2016; 63:385-93. 
Patel K, Bharatiya B, Mukherjee T, Soni T, Shukla A, Suhagia B. Role of stabilizing agents in formation of stable silver nanoparticles in aqueous solution: characterization and stability study. J Dispers Sci Technol, 2017; 38 .

Paul B, Bhuyan B, Purkayastha DD, Dey M, Dhar SS. Green synthesis of gold nanoparticles using Pogestemon benghalensis (B)O.Ktz. leaf extract and studies of their photocatalytic activity in degradation of methylene blue. Mater Lett, 2015; 148:37-40.

Gonzalez-Rubio G, Guerrero-Martinez A, Liz-Marzan LM. Reshaping, fragmentation, and assembly of gold nanoparticles assisted by pulse lasers. Accounts Chem Reserach, 2016; 49:678-686.

Sadeghi B, Mohammadzadeh M, Babakhani B. Green synthesis of gold nanoparticles using Stevia rebaudiana leaf extracts : characterization and their stability. J Photochem Photobiol B Biol, 2015; 148:101-6.

Shah M, Fawcett D, Sharma S, Tripathy SK, Poinern GEJ. Green synthesis of metallic nanoparticles via biological Entities. Materials (Basel), 2015; 8:7278-308.

Sinha I, Mukherjee AK. Interaction forces between nanoparticles in Lennard-Jones (L-J) solvents Interaction forces between nanoparticles in Lennard-Jones (L-J) solvents. J Phys Conf Ser, 2014; 490:1-5.
Tippayawat P, Phromviyo N, Boueroy P, Chompoosor A. Green synthesis of silver nanoparticles in aloe vera plant extract prepared by a hydrothermal method and their synergistic antibacterial activity. PeerJ $2016 ; 1-15$.

Yamamoto M, Kashiwagi Y, Nakamoto M. Size-controlled synthesis of monodispersed silver nanoparticles capped by Long-Chain Alkyl carboxylates from silver carboxylate and tertiary amine. Langmuir, $2006 ; 22: 8581-6$.

Yu J, Xu D, Guan NH, Wang C, Huang KL, Chi DF. Facile onestep green synthesis of gold nanoparticles using Citrus maxima aqueous extracts and its catalytic activity. Mater Lett, 2016; 166:110-2.

How to cite this article:

Arief A, Nasution FW, Zulhadjri, Labanni A. High antibacterial properties of green synthesized gold nanoparticles using Uncaria gambir Roxb. leaf extract and triethanolamine. J Appl Pharm Sci, 2020; 10(08):124-130. 